The boundaries of the social have been stretched by recent scholarship in sociological animal studies. Social theory has been challenged by the posthuman turn (Cudworth, 2011a; Peggs, 2012; Taylor and Signal, 2011), and empirical work on families and households, popular culture, rurality, work and even sleep has begun to open up to the presence of the myriad other creatures that make up social worlds (respectively Charles, 2016; Cole and Stewart, 2014; Wilkie, 2010; Coulter, 2015; Hsu 2017). Much of this research, almost inevitably, relies on standard practices in both sociological research and in the representation of non-human beings and things. That is to say, non-human animals are included via humans talking and writing about them. We may include other animals in our projects, but we do so predominantly through standard human-centred methods.

This paper reflects on a piece of research characterised by such contradiction and thereby considers the difficulties and possibilities of more-than-human methods, specifically ethnography. The data which provides the scaffolding for the empirical reflections is drawn from two sources: field notes observing interactions between "packs" of dog and human walkers and interviews with those living with dogs. What was methodologically distinctive, was that the majority of interviews were 'go-along' or 'walk and talk' where the researcher and two of the dogs-of-her-heart walked with human interviewees and their $\operatorname{dog}(\mathrm{s})$, allowing for observations of human/dog and dog/dog interactions also to be recorded. Other interviews were undertaken at interviewees' homes or in public places where the interviewees' animal companions were present. In addition, there was a period of intensive immersion - an ethnographic diary kept for a calendar year in the London field site which recorded events, interactions and routines of dogs, humans and other beings and things in the space of 'dog walking'. This paper does not provide a map of the resulting data and its many themes or reflect on the autoethnographical material from the diary data. Rather, it considers some of the ways in which conducting research with and about dogs alters both the data you obtain and the ways in which you understand the data collection process. The paper moves through first, a discussion of the 'animal turn' in sociology and sociological resistance to it (Cudworth, 2011a; Peggs, 2012; Shapiro, 2002; Whatmore, 2006; Wilkie, 2015); and second, the animal turn in methodology (Charles, 2016; Taylor, 2012), in particular, in ethnography (Hamilton and Taylor, 2017) before discussing the methods used in this project and some of the practices and events that emerged. 


\section{Animalizing sociology}

Some years ago I was about to speak at the British Sociological Association (BSA) Conference on a panel on violence, when an elderly white man stood up and enquired, very audibly, of those sitting in his vicinity, 'Is this the paper on animals?' When it was confirmed that, yes, a paper on systemic violence towards non-human animals was about to begin he declared 'Right, I'm off', and left the room not altogether quietly. For Rhoda Wilkie, this is perhaps an example of the worst kind of sociological reaction, exemplifying a "rigidly-minded" response to what is perceived to be an "island of scholarship' that lies outside of sociology's remit" (2015: 326). Lest it be thought that such responses are the preserve of older, white, male British sociologists, another experience at a BSA conference saw an older, white, British, male sociologist full of enthusiasm for a paper 'on animals' which I gave. In this case however, the sociologist happened to be Ted Benton who made an important early in intervention in sociological animal studies in the UK (Benton, 1993). Since such pioneering work, and despite increased sociological interest, this, as Arnold Arluke puts it "can hardly be called a flood" (Arluke 2003: 28).

Sociology, like other social science disciplines has generally understood there to be a fundamental "discontinuity between humans and animals" (Noske, 1993: 187). Considering species as a socially constituted category has proven difficult for a discipline whose boundaries were historically constituted around the designation of an arena for study - 'the social' - which was defined as exclusively human (Cudworth, 2011a: 20). Thus thinking about other animals has tended until very recently to be understood as at the fringes of, or tangential to, sociological concern (Whatmore, 2006: 604). The vast majority of sociologists continue to write for example, as if all household dwellers were human, taking little account of empirical work on interactions between humans and the non-human animals who are so often to be found in the 'home' (for example, Charles, 2014, 2016). Thus it cannot be said -at least not yet -- that sociological animal studies has moved "from the margins to the centre" (Taylor and Twine, 2014).

Moving 'to the centre' was a motif for feminist academic work for example in women's studies (Aaron and Walby, 1991) and black feminism (hooks, 1984) and a comparison is invited. The gendering of the mainstream in sociology has been profound and there are grounds for optimism that the 'animal turn' is here to stay. In examining the status of another interdisciplinary field, Human-Animal Studies (HAS), Ken Shapiro locates it as 
"solid, at the margin" (2002: 331). Yet since the early 2000s we have seen the advance of interest in HAS evidenced in conferences organised, journals, books, papers and special issues in Australasia, Canada, Europe and the US (Shapiro and DeMello, 2010: 307). It also would seem that youth is on the side of species inclusion. Leslie Irvine speculates that the future and success of the Animals and Society Section in American sociology lies in the hands of "graduate students who have the courage to challenge the field's outdated ideas about animals" (2012: 127).

\section{Animalizing method}

Multispecies studies compel researchers to go beyond their disciplinary boundaries (Birke and Hockenhull, 2012). The challenges of multispecies research has already led some to consider that HAS and multi-species work may be able to transform orthodox "methodologies that hitherto were imbued with anthropocentrism" (Segerdahl, 2012: 1567). What methods might be open to capturing "co-habitation, co-evolution, and embodied cross-species sociality" with a multitude of critters'? (Haraway, 2003: 4). Observing people and other animals, and talking to people about their lives shared with other creatures and their engagements with them seems an obvious starting point. Yet this kind of ethnography is necessarily problematic. We human subjects are those who decide what and how to collect data and how to present it, and this inevitably involves representation; a representation that is more difficult when those we represent are not human and often share a tiny amount or nothing of our language (Sanders and Arluke, 1993). We observe, record, speak and write and it is unsurprising therefore that most usually what we find begs "the obvious question, where are the animals themselves in this research?" (Hamilton and Taylor, 2017:2). There are also ethical questions raised - even if we manage to represent animals in our research, what do those represented (either individually or collectively) actually gain from our enquiries and academic outputs? (see Gaard, 2012).

The use of ethnographic observation and interviewing in field sites where humans and other creatures interact has used traditional sociological methods effectively in capturing the ways in which humans and other animals make relations and interact. Sociological ethnographic work has been undertaken in various contexts such as animal shelters (Alger and Alger, 1997, 2003b; Irvine, 2004), veterinary clinics (Sanders, 1993), living and playing 
with 'pets' and dog training sessions (Arluke and Sanders, 1996; Sanders, 1999). Such studies have been important in demonstrating the ways in which animal practitioners and owners $\mathrm{s}^{\mathrm{i}}$ of animal companions understand the animals they work and/or live with as persons with their own views about the world. Janet and Steven Alger's work on human-feline relations emerging from their ethnography of a cat shelter used observation and interviewing to show how cats interfere with human activities in order to make their preferences known, exercise choice (where to eat and sleep, for example) and display emotional states (Alger and Alger, 2003). Irvine found that would-be adopters of animals attempt to communicate with the animals they encounter and read relations into those encounters:

The dog then turns over, stands on her hind legs, and places her paws on the woman's thigh. The woman brings her face so close that the dog can lick her. The woman laughs and talks softly to the dog for a minute, saying, "Would you like to come home with me? Do you think we can be friends?" (Irvine, 2004: 90)

From such observations we gain an insight into the ways in which co-becoming of companion species relations is developed. Irvine's combination of ethnographic observation (in both a shelter and in dog parks) and her interviews with those potential adopters of animal companions gives insight into the texture of lives people live with animal others.

Irvine suggests that close attention we pay to animals enables us to interpret their behaviour and physical cues and to communicate with them at some level. It may be that what Irvine, the Alger's and I have researched is 'easy pickings' because of the possibility of reading across species when it comes to relations with cats and dogs. Yet of course, we may have read everything wrongly for animals also behave in ways that are sometimes counterintuitive to us, concealing, at least to human eyes, that which we-as humans-are often able to partially or wholly reveal to each other (Hamilton and Taylor, 2017: 8).

For those who identify with 'multi-species' scholarship rather than human-animal studies, this does not go far enough. While HAS has focused on people's relationships with animals or a particular species "a multispecies approach focuses on the multitudes of lively agents that bring one another into being through entangled relations" (Van Dooren et al, 2016: 3). I am not convinced that differences in the field are so marked. The common thread in 'multi-species scholarship' is "understanding what is at stake-ethically, politically, epistemologically-for different forms of life caught up in diverse relationships of knowing and living together" (Van Dooren et al 2016: 5). Yet I do not think that those working on 
relations with cats or with dogs in the way that Irvine has would disagree. The difference may really lie in the scope, i.e., that multi-species work is often looking at many, or more than two, species in interaction. Anna Tsing's (2015) work on the matsutake mushroom draws in multiple species and relations of migrant workers, corporations, forests and their management, for example.

Tsing's (2011: 19) "passionate immersion" in the lives of fungi, plants, humans and other animals captures ways of being and emerging in ethnographic form. Anthropologist Tim Ingold defined 'ecological anthropology' as a sub-discipline that contextualizes how "human beings and other organisms are bound in webs of life" (Ingold, 2012: 428). Might our encounters in the more-than-human world be best brought into written form as ethnographies that give non-human others vitality, presence, perhaps "thickness" on the page and in the minds and lives of readers, ask Thom van Dooren and Deborah Bird Rose (2016: 84-5)? Yet as Helen Kopnina (2017: 347) argues, this alone is insufficient, for particularly where the suffering of non-human creatures is concerned, observation and thickness of presence cannot do all the work for us -- a standpoint is also required. She concludes that while "the rhetoric of entanglements is sympathetic to nonhumans, it remains largely conventional" (2017: 351). As Hamilton and Taylor note, multi-species ethnographies can sometimes not help but "fall into the trap of prioritising human knowledge" (2017: 8).

Despite such caveats, whether scholarship identifies as human-animal or multispecies, ethnographic observation and conversations or interview styles related to it do enable humans and other creatures to be present, even if we cannot, ultimately get away from ourselves as human researchers. Ethnographies might invite curiosity about other ways of life (Van Dooren and Bird Rose, 2016: 86) and enable us to better understand its fragility and (often shared) vulnerabilities. They also pique our curiosity for while I had walked with dogs for many years, it was only when I wrote what I had observed that I realised that I had not really looked before. Garry Marvin (2005: 4-6) might explain this in terms of the different degrees of attentiveness required by seeing, looking, watching and observing. While I had years of seeing dog and human walkers (registering their presence) I had not really "taken notice" and paid the concentrated attention of the observer. In addition to making other creatures more visible, ethnography can enable "the emancipatory and critical endeavour of posthumanist scholarship" (Hamilton and Taylor, 2017: 174). An 
emancipatory agenda was my ethical project in relation to my research. I intended not only to map the ways in which human and dog lives are entangled and altered in species interaction, but also to consider the difficulties experienced by dogs and their humans as a result of the property status of dogs (including the documenting of histories of abuse in the lives of adopted dogs), restrictions on the movement of dogs in public space and the challenges to 'living well' as companion species.

\section{Walking with and talking dogs}

Most of the interviews I undertook for my project were 'walk and talk' or mobile interviewing, accompanying informants as they go about their daily routines and asking questions along the way (Hall, Lashua and Coffey, 2006). Participants were accompanied on their usual route, at a time of day most convenient to them; the priority being to put people and dogs at ease and talk to the human participants in a situation where they were dogfocussed. Some interviewees chose other locations, such as pubs, cafés or their homes. ii The illustrative material that follows is taken from two ethnographic sources semi-structured interviews with people who live with dogs, and observations which were (audio) recorded. Field notes were kept in the form of an ethnographic diary of encounters with dogs and their people in part of London's Lea Valley Park, recorded daily for a calendar year across 2009$10^{i i i}$. This gave a detailed picture of the nature of this particular community of dog walkers and their interactions over an extended period. In addition, material is drawn from semistructured interviews with dog owners, investigating their relationships and everyday lives with canine companions. Thirty seven interviews were undertaken in 2010 and 2011 with people walking dogs on the marshes which form part of the Lea Valley Park. Relocating to a village in rural Leicestershire meant I became part of another community of dog walkers and enabled me to test the extent to which locality affected the data. Thus a second phase of interviewing was undertaken in 2014 where fifteen interviews were undertaken with people walking dogs in and around the village. ${ }^{\text {iv }}$ There were however, no substantial differences in data obtained from interviewees living in urban and rural locations; an unexpected finding.

I was drawn to walking interviews as a way of both maximizing authenticity and trying to include dogs in my project. While it has lately attracted attention, walking as a research device is not a recent innovation (Bates and Taylor, 2017). In an important early paper, Margarethe Kusenbach (2003) argues that 'go-along' interviewing has the potential to access 
some of the transcendent and reflexive aspects of lived experience. She draws on urban ethnographic fieldwork in arguing that mobile interviewing enables the teasing out of complex and subtle meanings of place in everyday experience and practices. Kusenbach (2003: 462) argues that observation alone cannot access peoples' experience, while regular 'sit-down interviews' take interviewees out of the environment where the activities you want to research are taking place. 7In both study sites, I was researching my 'own' community of dogs and humans ${ }^{v}$ and thus the 'go-along' interview, combined with the kind of intense observation of the space recommended by Kusenbach seemed an excellent choice because it enabled research in a space where people usually encountered me, and in a well-established situation. What I undertook were what Kusenbach recommends as 'natural' go-alongs which have the key advantage I was looking for, a greater degree of authenticity than might be possible in unfamiliar settings:

For the purpose of authenticity, it is crucial to conduct [...] 'natural' go-alongs. By this I mean go-alongs that follow informants into their familiar environments and track outings they would go on anyway as closely as possible, for instance with respect to the particular day, the time of the day, and the routes of the regular trip. (Kusenbach 2003: 463)

As my sample of humans and dogs were necessarily those who walked with dogs and who undertook what they referred to as a 'proper walk' (that is, not a walk on streets and a walk that is relatively long), the time window - of between 45 and 90 minutes - ensured no disruptions to the regular routines of human-dog walking packs and was also happily what Kusenbach refers to as the "optimal" time for a go-along encounter (2003: 464). The only disruption to routine was for my research assistants, and for my older dog Kevin (aged thirteen when the project began), although fit and enthusiastic, I did wonder whether I was asking too much.

The two field sites suggested that there are specific spaces of dog walking - edgeland spaces - that are different to other venues where dogs and dog owners may encounter each other and "hang out". In the UK, many urban dwelling dogs are walked in public parks or around streets. "Dog parks", or fenced areas of public parks where dogs may be "off-leash" (or lead) are relatively rare in the UK (compared to the US); although lead-only dog walking is increasingly specified. Edgeland spaces however, are not subject to the levels of surveillance apparent in public parks and enable off-lead walking. The human walkers in this study saw edgeland spaces as those of relative freedom for dogs, as one put it: "It's not a proper walk if 
I don't bring them [her dogs] here [the marshes of the Lea Valley Park]. They love it here because they can do their thing, run about with their people [other dogs], rootle around...".

The dog walkers of a village in rural Leicestershire navigate fields with farmed animals and crops, crossed by official routes and meander paths. Movement along paths leaves room for some interaction, but it is in places of congregation -- by hedges at the sides of fields, on farm tracks or in less managed areas of recreation grounds - that people and dogs gather and "hang out" together. The Lea Valley Park in East London is more traditional marshland that has been "upgraded" with paths for walkers and cyclists. It is seen by some of its users as "countryside" and there is an abundance of wildlife. In testament to its ambiguous status however, viaducts crossing the Park are decorated with graffiti and parts are edged by housing estates. There is much space for meeting and stopping and the relatively open landscape encourages gatherings of packs who know one another. Kusenbach describes the 'go-along' as a form of "deep hanging out" (2003: 265) which perfectly describes elements of my roaming interviews, although my hanging out was more directed - while I followed the routes of the packs I and my research team accompanied, I had my questions invisibly filed waiting for the best moment to slip them in.

A wide variety of dogs were involved in the study including Airedale, Jack Russell, Staffordshire and Norfolk terriers, Schnauzers, German Shepherds, varieties of sighthound and spaniel, collies and retrievers, designer mutts such as Cockerpoos and Goldendoodles and multivariate 'proper mutts' such as those described by my interviewees as "a combo of Great Dane, Mastiff, English bulldog crossed with Staffie" or "a typical British mutt circa 1972, a collie/lab sort of thing". The human participants had a wide range of occupations ${ }^{\mathrm{vi}}$ and crossed divisions of class and wealth but were overwhelmingly white and mostly female. Similarly to studies on the 'family' (Charles and Aull Davies, 2008) or those on 'pets' within the home (Fox, 2008), I found more women than men to interview, particularly in the rural study site where twelve of the fifteen interviews were with women, and three men were interviewed together with their female partners ${ }^{\text {vii. }}$ In part, this is because the majority of dog walkers observed in both locations were female, but is also likely to be because women are less reserved about speaking about their everyday lives and homes, or the qualities of their relationships. The observational material and the interviews chart the practices of "responsible" dog owners who walk dogs regularly and have close bonds with them. There were different levels of interaction between groups of walking packs and different 
relationships emerge between different animals in their interactions, but whatever the strength of bonding I did find that dog walking communities are always constituted by and through dogs as well as by their human companions (Cudworth, 2017). It is fair to say that the data for this project is also co-constituted as we were a "research pack". This certainly changed the data I was able to collect and imbued it with specific features.

Human laughter is a feature of the interview data. In their study of the changing nature of family in which people proffered material on their relationship with animal companions, Charles and Aull Davies (2008) considered the use of laughter by interviewees to be an attempt to lessen the impact of including animals in their discussions of family, or to reflect ambivalence about revealing too close a relationship. In this project, some of the laugher may be due to such embarrassment, but also it may simply be that, as one interviewee put it, dogs are "just hilarious" and that retelling stories of lives lived with dog companions makes people laugh. At some points in the interviews, people had to pause because of laughing, or laughed so hard that they had tears in their eyes. Needless to say, writing this paper has made me smile.

\section{Pack research}

I began the research working alongside two dogs - Gypsy an easy-going female whippet-lurcher and Kevin the Jack Russell Terrier, a small man who considered himself to be big. Kevin and Gypsy were my research assistants for the 'London phase' of the project and came with me on every walking interview and to those conducted in other locations - usually people's homes or otherwise public spaces, specifically a pub and a café both located in the fieldsite. On the occasions when people came to my home, the dogs were always present. The dogs' involvement was crucial - they secured legitimacy in the field and interactions between people and dogs stimulated and provoked responses in interviews. In the second phase, losing the aged Kevin had meant a new dog in my life, Ruby; to whom I often refer as 'the dog that was sent to try me'. While Gypsy is a relaxed soul, at ease in the world, Kevin and Ruby were/are of a nervous disposition and had/have very clear likes and dislikes - of both certain other dogs and certain other dogs' human companions. Ruby in particular is a highly strung combination of great affection and significant aggression towards both dogs and humans. She tries me because, as a friend described, she is "so resentful of human control". And sadly for Ruby, in a human centred world, some level of obedience is necessary 
for life. Both the interview sample and what could be observed is shaped by the relationships of 'my' dogs, to others. In order for Kevin and Ruby, to be involved therefore, I did not walk and talk with 'packs' of dogs and companion humans whom 'my' dogs disliked. This would have been stressful for all concerned and was the most significant factor in the selection of the interview sample viii.

Gypsy, Kevin and Ruby were not 'official' research dogs, as was the late Ms Cayenne Pepper who gained research status at the University of California Santa Cruz in order to be able to accompany Donna Haraway to her office (Haraway, 2008: 206). Haraway argues however, that while Cayenne's official status was about securing her company on campus, the real research role Cayenne assumed was in living with Haraway. In the work of training, dogs and humans learn, Haraway says, how to "play with strangers" (2008: 243). This process of co-becoming enables Haraway to assert that in producing the chapter on agility, play and training for When Species Meet it was "not a literary conceit" to say that she wrote the chapter with Cayenne, but rather, "a condition of work" (2008: 205). Perhaps living with a dog who I know resents her status, I am very sensitive to the power relations of training in ways Haraway is not. In this project, Kevin, Gypsy and Ruby were field researchers, and their behaviour sometimes illustrated my own 'deficiencies' in training. At times, my research assistants chose to interrupt an interview with a human by barking, so that transcripts are frequently peppered with:

Interviewee: Shhh!

Interviewer: Kevin!

Interviewee: We're doing an interview here, Kevin

Interviewer: Kevin! Enough! Sorry about that, he barks for no reason sometimes, he seems to just enjoy it. Where were we?

Interviewee: Yeah, so no, so I haven't formed friendships in terms of beyond the walk environment...

In other cases, my research assistants appeared to have their own research agendas. On occasion the lovely Gypsy would disappear to sample some of the smorgasbord of delights (decomposing critters, various kinds of poop) offered in our field site so that interjections of "come on Gypsy!" or "hang on a minute she's eating crap again" were common. On occasion, being a relatively young dog (four years old) at the start of the project, she would decide on her own route with the dog we were accompanying:

Interviewer: Where have they gone? [pause] There they are over there - got their own agenda there 
Interviewee: Yeah, sneaking off together, even - one minute he's pretending they don't like each other and now they're gonna elope [some time spent going back and calling, a slight change of route] Alternatively, she might set out on her own:

Interviewer: Oh there she is. Where have you been? She's frightened of that bridge as well. She doesn't like crossing it

Interviewee: Is she alright with the other one though? [followed by a digression discussing the various bridges across the river and which dogs dislike which ones]

When Haraway (and others) speak of dogs as co-producers of knowledge in the laboratory as subjects of scientific experiments it unsettles me greatly. This is often the extraction of knowledge from the labour and suffering of animals rather than anything remotely like a joint endeavour. Here however, wandering or sitting around with other humans and other dogs meant that the data is slightly dog-shaped. At the time, I understood dog incursions into the smooth running of an interview with a human to be interruptions, delays, spoiling the flow of a narrative and making the experience disjointed for my human interlocutor. I now think it might have been more interesting to have been less anthropocentric and more dogocentric; to try and understand more of how dogs engaged (or did not) with the process . It was certainly the case that there is inequality embedded in my processes and in my findings for I prioritised one side of the human-dog relationship in this research; I did not treat all my participants with equal seriousness (Birke and Hockenhull, 2015: 15-16).

My 'walk and talk' interviewing remains both a human and a human-centred method. It was the human participants who were accompanied on their usual route. How much more might I have gained had we let the dogs decide the route? Ironically, it may be that dogs exercised more agency when interviews took place in the home. My research assistants in the field had very little say, ultimately. Interviews in the space of home still featured interruptions - barking dogs, or dogs otherwise influencing the space (sitting on people or furniture, farting, nosily dreaming, attempting to 'steal' human food or drink, chewing furniture or clothing and so on) and in turn this led to shifts in topics and foci of human conversation.

In perhaps the most interesting case, within the first ten minutes of my first interview, Kevin the Jack Russell actively participated in the emergence of a dog fight. I am walking with two women and their four lurchers when we encounter a man coming towards us with a border collie: 
Interviewee 1 - Rory's 10 or 11 this year...oops, collie alert, grab him [to partner] they hate them with a passion [to interviewer]

Interviewee 2 - they all hate them [pointing to Rory] and if he goes, then they'll all go [before we can put the dogs on leads, the border collie runs up to us, fast, snarling with teeth bared, Kevin is misbehaving and winding it up. Barking, snarling, Interviewee 1 loses her grip on the collar she is holding and Rory goes to attack the collie 'get here boy' 'Rory no!' 'away' 'get away now, come on' etc. Kevin and Rory get inspected for damage]

Interviewee 1 - what's that [on Kevin] is it mud or blood?

Interviewer - mud, I think it's just mud, that's ok

Interviewee 1 - off to a good start! [laughing] What happened there?

Interviewee 2 - it's Rory, naughty dog, Rory

Interviewer - [of Kevin] it's him, he started it!

Interviewee 1 - [of Rory] picture of innocence, look at him now [laughing]. It's collies, always a collie.

My initial reaction on completing the interview was disappointment that all had not gone smoothly and relief that none of the dogs had been hurt. In honesty I would have to admit to being embarrassed that Kevin failed as research assistant! Yet Kevin and Rory's intervention impacted on data collection. In the immediate aftermath of this skirmish, we discussed what happens when dogs dislike other dogs (on grounds of breed, or of personality), how this shapes the patterns of packs of human and dog walkers you socialise with, how it influences times and routes of walking, the experience of walking, the relationship with particular dogs and so on. I had not thought to ask about such matters yet every subsequent interview contained discussion of varying lengths about cross-pack interactions and this became a particular theme in the data on dog walking as generative of a particular kind of community (Cudworth, 2011b, 2017). While Birke and Hockenhull are right to say that we cannot interview non-human animals for their view on relations with humans, in this case I think we did have a glimpse of what might "matter to the animal from his or her point of view" (2012: 19).

\section{Ethics}

Interviewee - [to dog] Jago, did you give your consent?

[to interviewer] Do you want her paw print?ix

While I 'went along' with those who cared very much for the dogs whose lives they shared in this project, I was always very aware that the domination of non-human animals shapes the lives of companions in dog-land, and the lives of dogs are precarious. In the stories of 
the lives of dogs and their human companions that I listened to there are histories of neglect and of cruelty. For my human interviewees however, upsetting stories of the past lives of the dogs-of-their-heart, or of other dogs, were told willingly and people clearly felt that I needed to know such information. There was one question which I initially attempted to ask in interviews but quickly moved away from and this concerned the loss of past dogs, the possibility of losing a current dog and the possibility of a future without a dog (due to age, illness or infirmity). People quickly became visibly emotional and I considered another kind of project entirely would be needed in order to examine pet grief.

In thinking about the ethics and politics of multispecies studies Thom van Dooren, Eben Kirksey and Ursula Münster (2016: 16) consider that key questions "follow from asking cui bono: who benefits when species meet?" Such questions also apply to the ethics of my study - to what extent did I genuinely include non-human creatures; and to what extent was I able to acknowledge and challenge the asymmetries of power between dogs and owners? In this extract from the field notes, I encounter four people, all of whom I have interviewed prior to this chance meeting on a routine walk
...they ask how it goes. I say I've been interviewing quite a few people and they ask Kevin how he is coping with his new roles as my research assistant and all the walking. I say he had to walk 4 hours the other day. 'Poor Kevin, are you tired? She's terrible...etc'. 'You'll come in one day and find him on the phone to the Dogs Trust [UK charity]' and, impersonating Kevin: 'I've got this new job, but I never realised how much was involved. I'm an exploited working dog. Look at the length of my legs, they're worn away!'

While this was said in jest, Kevin was aging when he was involved with this project. That he was willing to be involved is without doubt - this dog loved to walk and always wanted to be where I was -- but whether I should have planned more carefully is an ethical issue. While the dogs I walked with seemed mostly to be enjoying themselves, my presence was disruptive of routines in ways I had not expected and caused unanticipated anxieties:

Interviewer: Where's Del gone?

Interviewee: I don't know. Let's get a trot on and I'm sure he'll be up ahead eating something disgusting.

[Debate as to which way to go and try to find Del. Walking fast now].

Interviewee: If I'm talking to somebody and not concentrating sometimes he will go off. If I'm focusing on him I can pre-empt what he's doing. I'm not panicking yet. Although he did run off and fell in between a narrow boat and the side of the canal, covered in green algae with just his little head poking out. If another boat had passed and washed it [the boat] in, there would have been nothing do 
be done. I had to do this commando roll and grab him by his collar. He's always sneaking off, looking for food, he knows there might be food on the boats he can get at. [We are running now] Bloody dog! Bloody hell, I am starting to panic. Poo, human poo, there's quite a lot of that in these woods, so we're going back in there. I'm just going through the process of where he would go to. Shame you're not making a documentary [name of author], how are you going to describe this excitement and my fear?

'What am I doing?' I thought to myself, running through a wooded area with my concerned human interviewee, panting into the microphone which is poking out of my top pocket. We ask everyone we see; a woman I know on a large bright pink bicycle is alerted and volunteers to make a circuit around the woods where Del is found, predictably, "eating something disgusting". What am I doing, disrupting the routine practices of this woman and this particular dog, a dog who was so emaciated when he was found wandering the streets and taken to a shelter that years later he still seeks out and eats whatever he can? Apart from this one experience, I did feel that the human interviewees enjoyed their experience. During one interview we come across another person who was soon to be interviewed. This prompts my interviewee to say to them "you are going to love this, it's great. It's just lovely just being able to talk about your dog to someone who wants to listen!"

\section{Conclusion}

In reflecting on my research project into the 'easy pickings' of people's relations with dog companions in two UK locations, I hope to have reinforced the importance of an ethnographic approach in capturing nuance in human relations with nonhuman animals by inscribing daily lives and practices. I hope also to have raised some questions about the inevitable humancentrism of ethnographic imaginations and the difficulties of bringing animals to the fore in our projects. Ethnography is a useful tool in attempting to map patterns of relationships and the ways lives are co-constituted in everyday practice. When I collected the data discussed in this paper, I considered that I was engaged in multi-species research, but the more I reflect on the data and how I obtained it, the more convinced I am that my practice remained human centred. While I consider 'walk and talk' methods were highly suited to this project, human talk and ways of seeing is inevitably privileged. My own research practice owed too much to anthropology and too little to ethology, and I see crossdisciplinary practices as vital in decentring the 'anthropos' from our 'ology', the human from our methods. 
I do believe that telling a good story about co-constituted lives that is both at the same time thick and critical on the page, is crucial in illuminating our reality as more-thanhuman social worlds that sociologists have a responsibility to represent. This is not just a question of 'science' but of politics and ethics. Not everyone might be interested in humananimal relations or multi-species scapes, but it is high time that sociology reflected on its anthropocentrism and positively embraced the notion of 'the social' as a complex network of multi-species lives, entanglements, dependencies and formations of power. This is an incredibly challenging task. For those of us who see ourselves as multi-species scholars, we are almost bound to fail. Certainly the ethical, political and practical problems I encountered with my study meant it was far less successful than it might have been. There are ethical questions which deserve further discussion, such as the ways in which University research protocols need address the inclusion of non-human animals as research participants in a range of disciplinary contexts (rather than tools of scientific experimentation). What would it actually mean for a dog to give their consent to be involved in this kind of research? Are dogs vulnerable subjects in that they cannot give consent in ways traditionally understood? Alternatively, might we need to revise our understanding of how we register and monitor consent in the research process? In retrospect I was far too conservative, but in the current academic context, conventional approaches are often repaid as low risk strategies in precarious times.

As animal sociologists however we need not only to be imaginative and dexterous in cross-disciplinary collaboration, we need to be brave. I do think that the time (of the Anthopocene/Capitalocene) is on our side, as is the (posthumanist) spirit of enquiry. Drawing on Haraway's (2003: 5) invocations, let us "run fast and bite hard" in securing the innovative data we need through creative means. Critical scholarship may well not be able to convince my detractor from the BSA conference of the error of his rigid world view but it may in future, I hope, be able to persuade an audience of sociologists to growl as he leaves the room.

\section{References}

Aaron, J. and Walby, S. (1991) Out of the Margins: Women's Studies in the Nineties. London: Falmer. 
Alger, J. and Alger, S. (2003a) Drawing the Line between Humans and Animals: An Examination of Introductory Sociology Textbooks. International Journal of Sociology and Social Policy 23(3): 69-93.

Alger, J. and Alger, S. (2003b) Cat Culture: The Social World of a Cat Shelter. Philadelphia, PA: Temple University Press.

Arluke, A. (2003) Ethnozoology and the Future of Sociology. International Journal of Sociology and Social Policy 23(3): 26-45.

Bates, C. and Rhys-Taylor, A. (2017) 'Finding Our Feet' pp. 1-11 in C. Bates and A. RhysTaylor (eds), Walking Through Social Research. Abingdon: Routledge.

Best, S. (2010) Animal liberation, human liberation and the future of the left. Available at http://www.drstevebest.org/RethinkingRevolution.htm. Viewed 21 March 2014.

Best, S. (2014) The Politics of Total Liberation: Revolution for the 21st Century. New York: Palgrave.

Birke, L. and Hockenhull, J. (2012) On Investigating Human-Animal Bonds: Realities, Relatings, Research, pp. 1-15 in L. Birke and J. Hockenhull (eds) Crossing Boundaries. Investigating Human-Animal Relationships. Leiden: Brill.

Charles, N. and Davies, C. A. (2008) My Family and Other Animals: Pets as Kin. Sociological Research Online 13(5). Available at: http://www.socresonline.org.uk/13/5/4.html Charles, N. (2014) 'Animals Just Love You as You Are': Experiencing Kinship Across the Species Barrier, Sociology, 48(4): 715-730.

Charles, N. (2016) Post-Human Families? Dog-Human Relations in the Domestic Sphere, Sociological Research Online, 21 (3).

Cole, M. and Stewart, K. (2014) Our Children and Other Animals: The Cultural Construction of Human-Animal Relations in Childhood. London: Routledge.

Coulter, K. (2015) Animals, Work and the Promise of Interspecies Solidarity. Basingstoke: Palgrave.

Cudworth, E. (2011a) Social lives with Other Animals: Tales of Sex, Death and Love. Basingstoke: Palgrave.

Cudworth, E. (2011b) Walking the Dog: Explorations and Negotiations of Species Difference, Philosophy, Activism, Nature, 8: 14-22.

Cudworth, E. (2017) Posthuman Community in the Edgelands, Society and Animals, 25, 4: 384-403. 
Fox, R. (2006). Animal Behaviours, Post-human Lives: Everyday Negotiations of the Animal-Human divide in pet-keeping. Social and Cultural Geography, 7(4): 525- 537. Gaard, G. (2012) Speaking of Animal Bodies. Hypatia Special Issue Animal Others, 27(3): 520525.

Hall, T., Lashua, B. and Coffey, A. (2006). Stories as Sorties. Qualitative Research 3: 2-4. Haraway, D. (2003) The Companion Species Manifesto. Dogs, People, and Significant Otherness. Chicago: Prickly Paradigm Press.

Haraway, D. (2008) When Species Meet. Minneapolis: University of Minnesota Press. Hsue, E.L. (2017) The Sociological Significance of Non-Human Sleep, Sociology 51(4): 865879.

hooks, b. (1984) Feminist Theory: From Margin to Center. Boston: South End Press. Irvine, L. (2004) If You Tame Me: Understanding Our Connection with Animals. Philadelphia, PA: Temple University Press.

Irvine, L. (2008) Animals and Sociology. Sociology Compass 2(6): 1954-71.

Kusenbach, M. (2003) 'Street phenomenology: The go-along as ethnographic research tool', Ethnography, 4(3): 455-485.

Kopina, H. (2017) 'Beyond Multispecies Ethnography: Engaging with Violence and Animal Rights in Anthropology', Critique of Anthropology 37(3): 333-357.

Marvin, G. (2005) Guest Editors Introduction - Seeing, Looking, Watching, Observing Nonhuman Animals, Society and Animals, 13(1): 1-12.

Nocella II, A., J., Sørenson, J., Socha, K. and Matsuoka, A. (2014) (eds) Defining

Critical Animal Studies: An Intersectional and Social Justice Approach for Liberation. Peter Lang: New York.

Noske, B. (1997) Beyond Boundaries. Humans and Animals. Montreal: Black Rose Books. Peggs, K. (2012) Animals and Sociology. Basingstoke: Palgrave.

Peggs, K. (2014) 'From centre to margins (and back again): critical animal studies and the reflexive human self', pp. 36-51 in N. Taylor and R. Twine (eds.) From the Margins to the Centre? The Rise of Critical Animal Studies. Routledge: London. Sanders, C. and Arluke, A. (1993) If lions could speak: Investigating the animal-human relationship and the perspectives of nonhuman others. Sociological Quarterly 34(3): 377-90. Sanders, C. (1993) Understanding dogs: Caretakers' attributions of mindedness in caninehuman relationships. Journal of Contemporary Ethnography 22(2): 205-26. 
Sanders, C. (1999) Understanding Dogs: Living and Working with Canine Companions.

Philadelphia, PA: Temple University Press.

Shapiro, K. (2002) Editors Introduction The state of Human-Animal Studies: Solid at the Margin!, Society and Animals, 10(4): 331-337.

Taylor, N. (2011) Can Sociology Contribute to the Emancipation of Animals? pp. 203-20 in N. Taylor and T. Signal (eds) Theorizing Animals. Re-thinking Humanimal Relations. Leiden: Brill. Taylor, N. (2012) 'Animals, Mess, Method: Post-humanism, Sociology and Animal Studies', pp. 37-50 in L. Birke and J. Hockenhull (eds) Crossing Boundaries. Investigating HumanAnimal Relationships. Leiden: Brill.

Tsing, A. (2011) Arts of Inclusion, or, How to Love a Mushroom, Australian Humanities Review, 50: 5-22.

Tsing, A. (2015) The Mushroom at the End of the World: On the Possibility of Life in Capitalist ruins. Princeton, NJ: Princeton University Press.

Van Dooren, T., and Bird Rose, D. (2016) Lively Ethnography Storying Animist Worlds

Environmental Humanities, 8 (1): 77-94.

Van Dooren, T., Kirksey, E. and Münster, U. (2016) Multispecies Studies Cultivating Arts of Attentiveness, Environmental Humanities, 8 (1): 1-23.

Wilkie, R. (2010) Livestock/Deadstock: Working with Farm Animals from Birth to Slaughter. Philadelphia: Temple University Press.

Wilkie, R. (2015) 'Multispecies Scholarship and Encounters: Changing Assumptions at the Human-Animal Nexus', Sociology 49(2): 323 -339.

\footnotetext{
iI avoid using the term 'guardian'. It does not reflect the material conditions of animal companions who are legally defined as property with minimal welfare safeguards in law. None of the human participants in my study used this term, describing themselves and others as 'owners'.

ii Twelve interviews were undertaken in non-mobile contexts/locations.

iii The times of these observations were similar in the mornings but varied in the afternoon/evening.

${ }^{\text {iv }}$ I did not consider it necessary to repeat a period of observation in the second site because my daily dog walking experiences did not indicate that I would gain different insights into human-dog relations than in the London site.

$\mathrm{v}$ Thus interviewees in both sites were previously known to me from dog walking encounters. No one I asked declined to participate although it was far more difficult to pin down potential male participants. All the women who agreed to be interviewed were interviewed, but I failed to interview five of the men who had agreed to participate within the timeframe.
} 
${ }^{v i}$ I knew the occupation of my many interviewees prior to interview, if not I asked this. The majority of interviewees were in paid employment. A minority were retired (2), were at home with young children (2) or did not work (5).

vii The gender split in the first phase of the interviews was 1:3 male:female, but in the London sample all the men were interviewed alone.

viii The personality of Kevin and Ruby was the factor of significance here; their sex was not a factor.

${ }^{i x}$ All the human participants in this study were given an information sheet and signed a consent form approved by my University. While the University Ethics Committee raised issues about human participants which I had to respond to, no mention was made of the dogs who were clearly present in the interview process. At the time, wanting to 'get on' with the research, I did not raise the issue of non-human participation but on reflection, this kind of research in the social sciences raises questions for current institutional procedures. 